\title{
Diphenhydramine-dependence Resulting From Self-medication of Antipsychotic- induced Extrapyramidal Symptoms
}

\author{
Faisal S. Shaikh M.B.B.S. \\ Yorkshire Deanery, Leeds, United Kingdom, faisal.shaikh@doctors.org.uk
}

Ann M. Mortimer M.D.

University of Hull, Hull, United Kingdom, a.m.mortimer@hull.ac.uk

Follow this and additional works at: https://jdc.jefferson.edu/jeffjpsychiatry

Part of the Psychiatry Commons

Let us know how access to this document benefits you

\section{Recommended Citation}

Shaikh, Faisal S. M.B.B.S. and Mortimer, Ann M. M.D. (2007) "Diphenhydramine-dependence Resulting From Self-medication of Antipsychotic- induced Extrapyramidal Symptoms," Jefferson Journal of Psychiatry. Vol. 21 : Iss. 1 , Article 5.

DOI: https://doi.org/10.29046/JJP.021.1.005

Available at: https://jdc.jefferson.edu/jeffjpsychiatry/vol21/iss1/5

This Article is brought to you for free and open access by the Jefferson Digital Commons. The Jefferson Digital Commons is a service of Thomas Jefferson University's Center for Teaching and Learning (CTL). The Commons is a showcase for Jefferson books and journals, peer-reviewed scholarly publications, unique historical collections from the University archives, and teaching tools. The Jefferson Digital Commons allows researchers and interested readers anywhere in the world to learn about and keep up to date with Jefferson scholarship. This article has been accepted for inclusion in Jefferson Journal of Psychiatry by an authorized administrator of the Jefferson Digital Commons. For more information, please contact: JeffersonDigitalCommons@jefferson.edu. 


\title{
Diphenhydramine-dependence Resulting From Self-medication of Antipsychotic- induced Extrapyramidal Symptoms
}

Faisal S. Shaikh, M.B.B.S., Ann M. Mortimer, M.D.

\begin{abstract}
Antipsychotic-induced extrapyramidal symptoms should be recognised and adequately treated. We report an unusual complication of not doing so: a patient's self-medicating to control these symptoms, which produced diphenhydramine-dependence.
\end{abstract}

\section{CASE REPORT}

$\mathrm{XY}$ is a fifty-year-old single gentleman living alone; his elderly parents live nearby. Paranoid schizophrenia was diagnosed at the age of 19 . He has had numerous psychiatric hospital admissions, but has been generally stable over recent years, while receiving support from the local assertive outreach team.

$\mathrm{He}$ is an only child. Slight cyanosis was present at birth, but early development was unremarkable. He grew up as an overanxious and sensitive child. At school he was bullied extensively, compounding anxiety symptoms to a degree warranting assessment by a child psychiatrist at age 13. Enuresis persisted until adolescence. Academically he did well, and left school with a number of ' $A$ ' levels. He went to university to read psychology, but left within a week, returning with early signs of paranoid schizophrenia: morbid thoughts emanating from passers-by suggesting that he hit others; he heard an echo of his thoughts shouted back at him; and he believed he was wired up so that people knew what he was thinking. Owing to the distress caused by these thoughts, he found it difficult to sleep and concentrate, and decided to abandon his university studies. Subsequently he had a number of short-term jobs, but since his midtwenties has been out of work. He has had brief relationships with women, but has no children, and never married. He smokes 40 cigarettes a day and drinks a variable amount of alcohol in the form of beer, not exceeding 10-15 units per week. Cannabis has been used on occasion. Apart from his mother's history of "emotional difficulties," there is no family history of psychiatric illness or substance abuse.

A variety of antipsychotic drugs have been prescribed, mostly as serial monotherapy: chlorpromazine, thioridazine, haloperidol, sulpiride, pimozide, risperidone, and trifluoperazine in oral form, as well as haloperidol and flupentixol depots. From the beginning of antipsychotic therapy, procyclidine 
was prescribed on a routine basis. But about ten years ago, in the midst of transfer between psychiatrists during a hospital admission, procyclidine was stopped, owing to suspicion of his misusing it. It was restarted at $10 \mathrm{mg}$ once a fortnight intramuscularly, following complaints of worsening akathisia, dysphoria, and insomnia. His pleas for reinstating the earlier dose went unheeded, as the psychiatrist had ongoing suspicion of potential misuse. The patient started to experiment with various over-the-counter medications, and found partial relief with diphenhydramine; he began taking increasing quantities, and within two years was taking $1600 \mathrm{mg} / \mathrm{d}$.

His care was transferred to our team five years ago. Recognizing diphenhydramine-dependence, as a consequence of poorly treated akathisia, olanzapine was substituted for other antipsychotic medication. The daily dose of diphenhydramine halved $(800 \mathrm{mg} / \mathrm{d})$, but no further reduction succeeded, despite numerous attempts by the multidisciplinary team engaged in his care. Two voluntary psychiatric hospitalizations took place, with the goal of detoxification from diphenhydramine; there was also a goal of initiating clozapine. On each occasion $\mathrm{XY}$ became unwilling to continue these interventions, and discharged himself. Our team concluded that it is dependence on the substance that is maintaining the patient's habit, rather than genuine need to treat residual extrapyramidal symptoms.

$\mathrm{XY}$ remains symptomatic with distressing auditory hallucinations and grandiose delusions; and he believes his thoughts are often broadcast on radio and television. Orientation, memory, and concentration are satisfactory; insight is poor, though compliance with medication has always been good. $\mathrm{He}$ functions adequately in his daily routine with support.

\section{DISCUSSION}

Extrapyramidal side-effects, common with high-potency, conventional antipsychotic drugs, include parkinsonism, akathisia, dystonia, and dysphoria (1). They result from dopaminergic antagonism in the caudate-putamen on postsynaptic cholinergic neurons, thereby increasing the cholinergic tone in the basal ganglia (2). Procyclidine, benzhexol (trihexyphenidyl), and benztropine are antimuscarinic anticholinergic agents that are especially useful in the treatment of antipsychotic-induced extrapyramidal side-effects. For akathisia, propranolol is more effective than the anticholinergic agents (3).

Abuse-potential is higher for benzhexol, apparently because it causes euphoria, than it is for procyclidine (4). Diphenhydramine is an $\mathrm{H}_{1}$-blocker that also has anticholinergic effects (1). It is commonly used as an over-the-counter hypnotic, but has been proved effective in the treatment of akathisia and dysphoria. Abuse-potential for antihistamines has not been established: casereports exist describing dependence, although without clarification about the 
context in which the dependence occurred (5). The case of diphenydraminedependence reported here, which we believe came about from a patient's frantic self-medication, underscores the importance of timely assessment, recognition, and treatment of antipsychotic-induced extrapyramidal side-effects, especially in patients on high-potency, first-generation, neuroleptics. In particular, the clinician must take care to recognise extrapyramidal dysphoria as well as akathisia. A risk of abuse of anticholinergic agents must be borne in mind, but the acknowledgment of risk should not lead to reactive and abrupt withdrawal of such necessary treatment.

\section{SOURCE INFORMATION}

From the Department of Psychiatry, Yorkshire Deanery, Leeds, UK (FS) and the Department of Psychiatry, University of Hull, Hertford Building, Cottingham Road, Hull UU6 7RX, UK (AM). Address inquiries to Ann M. Mortimer, M.D.: A.M.Mortimer@hull.ac.uk.

\section{REFERENCES}

1. Moore DP, Jefferson JW (2004). Handbook of Medical Psychiatry. Philadelphia: Elsevier Mosby

2. Cookson J, Katona C, Taylor D (2002). Use of Drugs in Psychiatry. London: Gaskell.

3. Sharma A, Madaan V, Petty F. Propranolol treatment for neuroleptic-induced akathisia. Prim Care Companion J Clin Psychiat 2005; 7:202-203

4. Pullen GP, Best NR, Maguire J. Anticholinergic drug abuse: a common problem?. Brit Med J 1984; 289:612-613

5. Craig DF, Mellor CS. Dimenhydrinate dependence and withdrawal. Can Med Assoc J $1990 ; 142: 970-973$ 